\title{
EL GIRO PERFORMATIVO DE LA IMAGEN
}

\author{
Victoria PÉREZ ROYO \\ Europa-Universität Viadrina in Frankfurt (Oder) \\ Perez@euv-frankfurt-o.de
}

\begin{abstract}
Resumen: En el camino desde la imagen cinematográfica convencional hasta la autónoma e interactiva de los escenarios sensibles, el cine se ha integrado con las artes escénicas dando lugar a una serie de híbridos como el expanded cinema o el cine interactivo. Se trata de un desarrollo en el que la imagen adquiere propiedades de sujeto, mientras que el cuerpo del espectador entra en diálogo con ella. En este texto se esboza una evolución del arte interactivo, desde los años sesenta hasta la actualidad, desde la cual se abordan con mayor claridad las implicaciones estéticas de lo que se podría llamar «el giro performativo de la imagen».
\end{abstract}

Abstract: From the conventional cinematographic image to the autonomous interactive one of sensitive stages, cinema has been integrated with performing arts, and so giving rise to a series of hibrid creations such as $e x-$ panded cinema or interactive cinema. In this process the image acquires the features of a subject, whereas the spectator's body is in turn involved in a dialogue with the image in front of him. In this text the development of interactive cinema from the sixties to the present is outlined in order to better 
tackle the aesthetic consequences of what could be called «the performative turn of the image».

Palabras clave: Interacción. Tecnología. Artes escénicas. Cine. Performance.

Key words: Interaction. Technology. Performing arts. Cinema. Performance.

\section{EL GIRO PERFORMATIVO}

La imagen bidimensional del cine y del vídeo comenzó en los años sesenta a sentirse incómoda dentro de sus propios límites debido a sus desajustes frente a un cambio de paradigma en la estética. La transformación del contexto artístico en aquellos años se orienta principalmente hacia la emancipación del espectador, una vía de desarrollo que en esos años se convierte en inaplazable ${ }^{1}$. Frente a la de repente incómoda situación pasiva del público se proponen dos tendencias divergentes y complementarias de mayor involucración del espectador en el plano de la recepción: bien mediante la creación de una complejidad mayor en la estructura de la pieza, bien otorgándole al receptor un papel activo y en ocasiones físico en la actualización de la obra.

La primera de ellas fue esbozada, si bien de forma insuficiente, por Umberto Eco en su Obra abierta (Eco, 1984: 63-92). Tal y como lo describe el teórico italiano, en esos años se opera un cambio en la concepción de obra artística: frente a una creación cerrada y concluida, siempre igual a sí misma, se prefiere una obra sin terminar, abierta, que debe ser completada o actualizada por el receptor; se trata de una pieza que no ofrece soluciones, sino que plantea enigmas a este para que los investigue. La apertura de estas piezas no es la inherente a toda obra artística (de primer grado), según la cual

${ }^{1}$ Uno de los factores que, quizá de forma indirecta, generó parcialmente esta urgencia por la emancipación del espectador se debe encontrar en la crítica del espectáculo elaborada por Guy Debord, según la cual en la imagen hipnótica de la pantalla lo que se observa en realidad es la actividad que le ha sido robada al espectador, su propia desposesión. En sus escritos los miembros de la Internacional Situacionista abogaban por el abandono del lugar pasivo tradicionalmente adscrito al espectador (y en un plano más general, al ciudadano) para favorecer en cambio una nueva situación en la que este se ve empujado al círculo de la acción y la fuerza colectiva y en situación por fin de elaborar un sentido de comunidad, radicalmente opuesto a la situación de los individuos delante de la pantalla televisiva o de los espectadores del cine frente a las imágenes proyectadas. 
cada receptor proyecta sus propias experiencias, memorias y conocimientos sobre la pieza; se trata, en cambio, de una apertura que se entiende como «vocación fundamental» de este tipo de creaciones: dejando de lado otros valores, la obra abierta concede relevancia especialmente al momento de la recepción estética, en el que la apertura no es una característica más, sino la condición misma del goce estético, el tema central; de este modo se opta por una creación determinada por un carácter procesual, con una estructura orgánica que permite el dinamismo y las interacciones en su seno multiforme y cambiante. Siguiendo esta nueva estética, el espectador debe ser liberado de su pasividad, de la fascinación que le causan las imágenes (o de su identificación con los personajes) para proponerle a cambio un espectáculo complejo que se plantea como un problema y que requiere su implicación analítica.

La segunda opción para facilitar que el espectador se vea envuelto en el hecho artístico se describe con mayor precisión con el concepto de giro performativo de las artes acuñado y teorizado por Erika Fischer-Lichte (2004: 9-30). Según la teórica alemana, el giro performativo implica sobre todo un cambio fundamental en la experiencia estética desde lo semiótico hacia lo performativo. El sentido de la obra no surge en la dialéctica hermenéutica entre significante y significado, sino en la creación de una vivencia para el espectador. Lo fundamental consiste en la constitución de un acontecimiento, de una experiencia compartida por creador y receptor, frente a la lectura o interpretación del objeto estético propias del paradigma anterior. Otra de las características que definen este giro se basa en la desaparición del objeto de arte como una entidad inalterable a la que el receptor puede volver a voluntad para comprobar sus hipótesis y encontrar nuevos significados; en su lugar surge una nueva situación estética en la que los anteriores polos de sujeto y objeto no se distinguen. Esta diferenciación, que resulta fundamental para las estéticas semiótica y hermenéutica, se diluye para dar paso a un acontecimiento procesual que envuelve al público en su creación; la dicotomía sujeto-objeto entra así en un comportamiento oscilante en el que ninguna de ambas posiciones se puede definir con precisión. Por último, el proceso de recepción se caracteriza por reacciones ya no sólo intelectuales, sino también fisiológicas, afectivas, volitivas, energéticas e incluso motoras: «No se trata de entender la performance, sino de experimentarla y de gestionar las experiencias que en el momento de la performance no se dejan controlar por la reflexión $»^{2}$ (Fischer-Lichte, 2004: 19). De esta manera el espectador se en-

\footnotetext{
2 Traducción mía.
} 
cuentra obligado a abandonar su estatus pasivo de mero observador para verse arrastrado y sumergido en el acontecimiento de la obra.

Naturalmente, el cine no escapó a este cambio de paradigma; al intentar adecuarse a las nuevas exigencias de participación del público procedió a una revisión de sus propiedades y de su lenguaje, lo cual inevitablemente condujo a la creación de géneros nuevos, vinculados a otros ámbitos de creación, concretamente a las artes escénicas. En este proceso, la imagen cinematográfica se encontró con una serie de limitaciones evidentes en el establecimiento de la narración: una encadenación de planos y secuencias montadas según un orden lineal predeterminado e inamovible que conforma una sucesión temporal hacia delante tan inmisericorde «como la ley de la gravedad», según la expresión de Weinbren (1992: 61). Otros impedimentos adicionales del cine para su adaptación al giro performativo eran, aparte de la unidireccionalidad de su desarrollo, la bidimensionalidad de la imagen y la imposibilidad de que el espectador influya en el suceso fílmico. Un espectador frente al cine tradicional se encuentra muy alejado de la posibilidad de afectar de alguna forma sobre el curso de los acontecimientos audiovisuales, de tomar un papel realmente activo en la configuración de la obra. La imagen cinematográfica desarrolla entonces una serie de estrategias para escapar a estos condicionamientos, dando lugar, entre otros resultados, a lo que se ha dado en llamar cine interactivo.

\section{CINE INTERACTIVO}

Bajo esta denominación una serie de autores se dedicaron a la exploración de formas de narración fílmica alternativas al cine convencional, en las que el acento se sitúa específicamente en la implicación del espectador en el evento artístico. Dentro de la variedad de actualizaciones de este término, Grahame Weinbren ideó un cine interactivo que, aunque parezca paradójico, no renuncia a las limitaciones inherentes de la narración, sino que se basa en la investigación sobre las relaciones entre las historias presentadas. Este creador ha explorado las posibilidades de activación del espectador sin alterar los estrechos límites de operación que el marco de presentación del cine tradicional permite: una de sus propuestas se basa en el modelo freudiano de análisis de sueños, en concreto, en el caso Wolfman (Weinbren, 1992: 5864). La narración que propone es la misma que la del análisis de un sueño: en una imagen onírica se condensan una serie de miedos, emociones, creencias y vivencias del soñador, que, en sí mismos, no constituyen ninguna narra- 
ción; sin embargo, en su análisis se revelan un conjunto de personajes, vidas e historias. La enunciación de las narraciones sedimentadas que la imagen onírica contiene, la explicación de las historias, miedos y sensaciones que subyacen a ella puede presentar diversos órdenes que, de una manera u otra, remiten a la misma historia general. Si el análisis del sueño se considera como estructura narrativa, es lícito afirmar que los elementos pueden asumir cualquier disposición y no obstante dar lugar siempre a la misma ficción. Para trasladar este tipo de narración a la pantalla cinematográfica el orden debe ser entonces considerado como irrelevante, de forma que la película se organice en torno a una estructura permutacional virtual; es precisamente en este punto en el que la implicación del espectador juega un papel decisivo, en tanto es consciente de que si bien el orden secuencial real es inamovible, el orden virtual (el que el espectador decide imaginar) depende en último término de su decisión. Esta estructura permutacional es la que Grahame Weinbren considera adecuada como posibilidad de sustraerse a la dominación de la estructura temporal lineal del cine narrativo.

Esta propuesta de Weinbren, no obstante, no coincide con la concepción general de cine interactivo; en su mayoría los experimentos cinematográficos han ido más allá en la reconsideración de las limitaciones de la imagen. En realidad, una vez definido el cine, tal y como lo defendía Charles Atlas (Rosiny, 1999: 23), como el arte de organizar hechos audiovisuales en el tiempo, no parece imposible un cine interactivo, en el que el cuerpo del espectador también juegue un papel relevante y en el que el giro performativo de la imagen cinematográfica se realice plenamente. De acuerdo con esta descripción, no es característico del cine un orden predeterminado e inamovible de secuencias audiovisuales. Surgieron así una serie de géneros híbridos que plantearon la reconfiguración de los elementos cinematográficos del cine convencional: la reorganización de proyector, superficie de proyección, sala de cine y masa de espectadores. Creadores como Jeffrey Shaw o Grahame Weinbren recurren a estrategias tales como la ampliación y multiplicación de la superficie de proyección, a tácticas en el plano de la organización fílmica, así como a la invención de alternativas en el establecimiento de la relación entre el espectador y la obra, haciendo explotar las convenciones del cine y dando lugar a múltiples variaciones y juegos con ellas. Estos experimentos se basan en el convencimiento de que la pantalla tradicional no agota las posibilidades de la narración en imágenes, con lo que favorecen su exploración exhaustiva, la ampliación y la superación de sus límites.

La obra de Jeffrey Shaw se puede considerar un caso paradigmático de búsqueda incesante de estrategias en la consecución de un cine interactivo, 
entendido este esencialmente como la introducción del cuerpo del espectador en la imagen o en el suceso fílmico:

Todos mis trabajos son, de una manera u otra, un discurso con la imagen filmica y con las posibilidades de hacer volar por los aires las limitaciones del marco de la imagen, de posibilitar a la imagen extenderse físicamente hacia el espectador o posibilitarle al espectador entrar virtualmente en la imagen (Shaw en Duguet, 1997: 29).

Las primeras obras en esta dirección de finales de los sesenta, denominadas Expanded Cinema, se podrían de hecho adscribir perfectamente al ámbito de la performance. La pieza Corpocinema consistía por ejemplo en una bola gigantesca de PVC sobre la que se proyectaban películas y diapositivas; en ella los espectadores podían intervenir sobre la imagen, entrar en los globos, jugar dentro y fuera de la cúpula con los elementos de la performance (espuma, polvos de colores, confeti o humo), lo que naturalmente transformaba la imagen proyectada. Todos los asistentes, incluidos los músicos, los actores y el público, participaban en la acción. En MovieMovie, obra del mismo periodo, la película se proyectó, junto con diapositivas y diversos efectos lumínicos, sobre una estructura que se iba inflando en el curso del acontecimiento. Al público se le guardaba, como en Corpocinema, la posibilidad de deformar las imágenes, moviéndose por el espacio e incluso saltando sobre la estructura. Con este tipo de obras la sala de cine se transformaba en una comunidad coreográfica en la que nadie permanecía en el papel de espectador inmóvil, en la que el público tomaba decisiones y conformaba con ello un acontecimiento fílmico y performativo de acuerdo a un ritmo gestionado en común.

Estos experimentos se pueden considerar como pasos previos a otros desarrollos que desembocarían, con la introducción cualitativa de la tecnología digital en el ámbito artístico, en dos tipos de creación interactiva, en dos formas de relacionar al espectador con la imagen, en las que el cuerpo juega un papel fundamental. Por un lado, el arte medial interactivo: este tiene lugar en un contexto museístico y se define por establecer una relación íntima entre obra y espectador. La imagen cinematográfica renuncia a una masa de espectadores en silencio y oscuridad para privilegiar a cambio una recepción personal que influye positivamente en el desarrollo de la obra. Por otro lado, el escenario interactivo: este tiene lugar en el ámbito escénico y en él la imagen cinematográfica escapa a su estructura predeterminada para presentar una obra emergente que se crea a sí misma en un sistema de autoalimentación, motivada por el diálogo entre sus partes (actor o bailarín y elementos 
escénicos). La imagen cinematográfica se instala plenamente en el espacio reservado a las artes escénicas, se expande y adquiere propiedades de sujeto, se trata de igual a igual con el actor, con quien dialoga para generar de forma emergente una situación escénica cada vez distinta.

\section{INSTALACIÓN MEDIAL INTERACTIVA}

La primera de las opciones, la instalación medial interactiva, busca una participación real del usuario (el término espectador ya no es adecuado) en la transformación de la imagen que tiene ante sí; para ello lo aísla de la masa como público para darle a él personalmente la oportunidad de intervenir directamente en la narración. Gran parte de los artistas implicados en la búsqueda de formas alternativas de relacionar al público con el suceso audiovisual, así como en dotar de una cierta apertura al suceso fílmico desarrollaron un amplio espectro de intervenciones, para finalmente llegar a la instalación interactiva como solución satisfactoria; tanto es así que, esencialmente, por cine interactivo solía entenderse la colaboración del vídeo (o cine) con el ordenador en forma de instalación:

¿Qué es el vídeo interactivo? Bastante simple, un programa de vídeo que puede ser controlado por la persona que lo está usando. Normalmente esto significa un programa de vídeo y un programa de ordenador que funcionan como un tándem. El programa de ordenador controla el programa de vídeo y la persona frente a la pantalla controla ambos (Parsloe en Weibel / Lischka, 1989: 77).

Este tipo de creación requiere un solo espectador-participante frente a una pantalla en la que se ofrece un abanico de secuencias que debe ordenar o elegir. Suele estar situado en el contexto del museo o la galería, completamente alejado de la recepción del cine usual (una sala oscura en la que una colectividad de espectadores observan una pantalla situada frente a ellos). Este arte se orienta a una recepción individual (frente a la masificada de la sala de cine), personal (cada espectador o usuario plantea un recorrido distinto) y por ello, en principio, única. Jeffrey Shaw, en su exploración de los límites del cine, no solo experimentó con el expanded cinema, sino también con este tipo de instalaciones museísticas como Viewpoint (en la que, como indica el título, la preocupación por la mirada del espectador constituye un tema central), así como otras como The narrative landscape, con imágenes y texto digitales que el espectador puede controlar por medio de diferentes instrumentos. La solución definitiva efectivamente la ha hallado en este tipo de creación, la insta- 
lación interactiva, con piezas como The legible City, dotadas de interfaces mucho más sutiles en la introducción del espectador en la imagen. En esta pieza el espectador controla la dirección y la velocidad de su visita por la ciudad virtual a través del movimiento de su cuerpo en una bicicleta.

Grahame Weinbren optó, asimismo, por otras formas de cine interactivo (aparte de la comentada que se basa en el análisis freudiano de sueño). Para ello se introdujo, asimismo, en el ámbito de la instalación medial interactiva; creó así la película Erl King, basándose en una extensión del concepto de Maya Deren «desarrollo vertical» del drama fílmico, en la que el espectador puede intervenir según una serie de estrategias para cambiar el orden de las secuencias de la película. El espectador puede interferir en el desarrollo del filme para conocer las causas o consecuencias de una acción fílmica concreta o incluso para informarse sobre el efecto emocional que un hecho en el plano horizontal de la película pueda tener en alguno de los personajes. Detrás de las imágenes que están en primer plano en la pantalla se presuponen otras que explicarían o completarían la trama; estas se encuentran allí potencialmente y se puede recurrir a ellas en cualquier momento que el espectador lo desee. Weinbren lleva a la práctica con esta instalación una concepción de cine interactivo como construcción de una conversación entre usuario e imagen.

La interactividad en estas obras no constituye una característica opcional que ayude a definir su perfil y su funcionamiento, sino que pasa a un primer plano, definiendo su modo de ser fundamental y las formas de relacionarse con su entorno. «Para algunos, la interactividad no es un género artístico, sino un modo de existencia, un parámetro fundamental» (Duguet, 1995: 148). Son piezas cuyo propósito expreso se basa en la exploración de la obra por parte de los visitantes, quienes van formando progresivamente, a la vez que la interacción con ella, la propia percepción. El autor de una obra de estas características no pretende sorprender al espectador con imágenes novedosas que lo hipnoticen, sino abrirle nuevos caminos que él debe explorar; la tarea del artista no consiste así en crear las condiciones para una experiencia cognitiva, característica de la contemplación estética previa, sino que incluye el tomar parte en una experiencia que el mismo espectador conforma dentro de los límites que el sistema permite. Por otro lado, aparte de un mensaje concreto, la obra ofrece la experiencia de vivir el mundo que ella propone, constituyéndose la interacción misma como contenido. Las posibilidades de copresencia de los dos mundos (aparato y usuario) dentro de la misma forma de existencia (obra medial interactiva) se sitúan en primer plano, así como la reflexión del espectador suscitada por su presencia y su acción dentro de la obra de arte. Desde este punto de vista otros parámetros 
de la obra pierden relevancia, mientras que su valor como instrumento pedagógico de autopercepción y como medio que favorece la reflexión tanto sobre determinados comportamientos sociales, como sobre su propia actualidad aumenta en gran medida (Dinkla, 1997: 11). Por ello, para un enjuiciamiento crítico de este tipo de arte sería necesario sobre todo valorar el papel del receptor en el trato con el sistema, así como el grado de control o libertad que se le permite dentro del sistema de reglas dado. Aunque en muchos de los casos en el arte medial interactivo el diálogo entre usuario y sistema se reduce a una intervención tipo menú, en el que las opciones entre las que puede decidir el espectador son muy limitadas y están determinadas de antemano, existen otras piezas que descubren una interacción con un margen de acción suficientemente amplio.

En cualquier caso, estas investigaciones han dirigido el cine hacia nuevos territorios, lo han acercado indiscutiblemente a otras disciplinas. Mientras que este tipo de piezas han desplazado la imagen hacia las artes del espacio, la tendencia en la que se enmarcan las investigaciones de Shaw, especialmente el expanded cinema, suponen una orientación del cine hacia las artes de la escena (Duguet); esto supone una vuelta a la corporalidad, a la revaloración de la presencia real y el contacto interpersonal y a la irreproductibilidad de la obra artística.

\section{ESCENARIO INTERACTIVO}

La verdadera introducción de la tecnología digital y con ello de una imagen autónoma y abierta a transformaciones por parte del usuario en el espacio escénico ha dado lugar al segundo tipo de creación interactiva apuntada, el escenario interactivo. Existen una infinidad de instrumentos interactivos con los que se logra un diálogo del cuerpo con los parámetros escénicos, sean estos iluminación, sonido o imágenes de vídeo, siendo los que permiten una interacción con elementos visuales los más empleados actualmente ${ }^{3}$.

3 Dentro de estas aplicaciones se pueden distinguir dos tipos: las que funcionan con contacto directo y visible con sensores, o las que utilizan cámaras, células fotoeléctricas, sensores de movimiento o luces infrarrojas. Dentro de la primera categoría se utilizan por lo general objetos con interruptores o sensores que se llevan pegados al cuerpo y que suelen tomar como señales la presión sanguínea, el pulso, la frecuencia cardiaca, la presión sobre el sensor o el grado de apertura de una articulación del cuerpo, por ejemplo. Estos sensores se suelen llevar pegados al cuerpo o en la ropa, como unos zapatos o un vestido. El otro tipo está basado en videocámaras, que permiten un uso mucho más directo y sencillo, aunque son un poco más imprecisas en la captación del movimiento, como MidiDancer, Isadora, EyeCon, Kalypso, BigEye, DanceSpace, Image/ine o Eyesweb. 
Estos espacios requieren una determinada infraestructura técnica: en primer lugar, un sistema sensible basado en sensores o en cámaras que capte el movimiento o la voz del usuario. Según el programa y el sistema sensible existen numerosos valores para medir un movimiento, como por ejemplo: amplitud, dinámica, dirección, cercanía al suelo, cantidad de movimientos o situación espacial, entre otros. Este sistema sensible se encuentra conectado a un ordenador que interpreta las señales enviadas, las cuales son procesadas y transformadas por un software a tiempo real. Por último, se requiere un sistema de salida, en el que los datos sobre el movimiento recibidos e interpretados se traducen en órdenes a diversos aparatos, de manera que el movimiento original se transforma en un sonido, una grabación previa de música, una proyección de imágenes o de determinada gama lumínica; a ello se añade la posibilidad de la manipulación a tiempo real de estas señales, según el tipo de instrumento interactivo empleado. Según esta descripción, el papel del actor en un entorno interactivo sería el de mero instrumento, cuyo valor reside en la capacidad de crear una composición visual o acústica en la escena ${ }^{4}$. Sin embargo, para que se dé una auténtica interactividad (entendida entonces, no tanto como traducción de datos de unos soportes a otros, sino como comportamiento dialogal entre escena y actor) se necesita un tercer momento: la reacción del actor frente al entorno escénico que él mismo ha generado.

Lo común a la mayoría de manifestaciones interactivas es, resumidamente, el empleo del movimiento del cuerpo como factor que estimula los parámetros escénicos y que reacciona a tiempo real frente a ellos en un sistema de autoalimentación. De esta forma se produce un momento auténticamente creativo en la confrontación entre dos sistemas: el bailarín y el sistema interactivo; de ahí surge un diálogo que constituye el texto escénico, la obra misma, generada de forma emergente. La pieza, por lo tanto, nunca es igual a sí misma, no existe una versión correcta; no consiste en una representación repetible cada tarde, sino en un diálogo cada vez diferente dentro de una estructura más o menos flexible. De acuerdo a esta la condición netamente procesual que caracteriza a las piezas que emplean tecnologías interactivas, la creación con un entorno sensible se basa en un trabajo evolutivo a lo largo de los ensayos, en los que se han ido tratando y conociendo las diferentes configuraciones espaciales del sistema; la improvisación en la escena (que constituye la obra que conocen los espectadores) es la continuación de un diálo-

${ }^{4}$ De hecho, este fue el caso en la mayoría de las primeras piezas interactivas: el movimiento del cuerpo estaba reducido y limitado al servicio de una creación visual o sonora a través de la cual se demostraban las capacidades de cada instrumento tecnológico nuevo. 
go ya iniciado; el bailarín o actor parte, así, cada tarde de una cierta seguridad acerca de los efectos que su acción en el espacio sensible puede causar, a la vez que cuenta con un imprevisión relativa en cuanto a la reacción concreta. La pieza presentada no se considera (por lo general) una solución o un resultado que condensaría los mejores momentos de los ensayos, sino que, una vez más, se trata de un estadio de desarrollo de una investigación que el bailarín o actor lleva operando a lo largo de todo el proceso creativo, un paso más en el proceso de relación entre cuerpo e imagen.

La imagen proyectada, por su parte, no es inerte e inalterable como la del cine, sino que se trata de un ente cambiante, con diversas propiedades para cada escena, las cuales el actor o bailarín debe descubrir por medio de una investigación cinética. En este sentido, la imagen se convierte en el auténtico generador de la performance, llegando a asumir el papel de pareja de baile. Por estas razones y desde el punto de vista de la capacidad de respuesta autónoma de la imagen-contexto, la dicotomía entre sujeto y objeto deja de tener validez para dar paso a una relación mucho más compleja que la tradicional de las artes escénicas, en la que la acción teatral tiene lugar en un espacio vacío e inanimado.

En este escenario, por lo tanto, se mantienen una serie de principios presentes que definían el cine interactivo: carácter procesual, imagen con capacidad de cambio e interacción con el sujeto, involucración del cuerpo del usuario en el diálogo con la imagen, complejidad estructural de la obra - ésta ya no posee una forma única, sino que se elabora en colaboración con el usuario - y creación de un acontecimiento en lugar de una obra escénica única e idéntica a sí misma. No obstante, el propósito fundamental de emancipación del espectador que originalmente motivó estas transformaciones finalmente no se ha cumplido. Si bien las características descritas son ciertas, lo son en el caso del actor o bailarín, pero no para el espectador; la posición de este se sigue limitando a formar parte de una comunidad pasiva cuya función es observar un espectáculo, en este caso escénico.

Esta es la solución a la que se ha llegado en la actualidad, pero de hecho en las primeras creaciones interactivas escénicas la participación del espectador era uno de los objetivos fundamentales. De ahí radica, desde mi punto de vista, una de las razones principales de la confusión (que todavía subsiste en parte) respecto al término interacción. De esta forma el grupo alemán Palindrome ${ }^{5}$, pionero en el desarrollo y aplicación de tecnologías interactivas

5 Para saber más sobre Palindrome: Wechsler (2001: 191-202; 2003: 60-77). 
en la escena, creó en sus inicios las piezas Press Scape y Publikumsstück, en las que se generaba un entorno interactivo en el plano acústico. En el fragmento Public Sounds de la primera pieza, las cámaras se orientaban hacia los asientos de los espectadores para establecer un entorno medial, en el que el público era invitado a activar efectos de sonido levantando manos y brazos. El caos resultante de esta operación parece obvio: es de suponer que las diversas acciones del público se traducían en una masa de sonido indistinguible, en la que resultaba imposible reconocer la relación entre causa y efecto. Para que el funcionamiento del sistema se reconozca debe haber pausas y silencios, de forma que se distingan las acciones que motivan las respuestas por parte del sistema. Por ello, en los siguientes experimentos Palindrome decidió tomar un número limitado de participantes que asumieran las funciones de representantes del público. Así sucedió en Publikumsstück; en esta pieza, durante el intermedio de un espectáculo interactivo como los anteriormente descritos, se seleccionaban a unas ocho o diez personas del público a las que se les aclaraba el funcionamiento del sistema. A continuación Robert Wechsler, el coreógrafo, les enseñaba algunas muestras de movimiento, frases cortas que debían proporcionarles un cierto material coreográfico para probar poco después el funcionamiento del sistema. Tras un breve calentamiento ejecutaban su improvisación, la cual duraba entre dos y cinco minutos. Un baile pausado y un número de dos personas máximo para probar los efectos eran los criterios para ejecutar una improvisación interactiva que no resultara confusa. A pesar de que tan solo una parte del público probaba el sistema, el resultado era bastante satisfactorio, dado que la identificación emocional del público con sus representantes era mucho mayor que con los bailarines ${ }^{6}$. Estos experimentos pertenecían a una etapa de experimentación cuyo interés no radicaba tan solo en la voluntad de ofrecer un papel activo al público, sino también y en gran medida en ofrecerles acceso al funcionamiento de una tecnología radicalmente novedosa en aquel momento.

Como se ve en estas dos piezas, las dos preocupaciones mencionadas al comienzo (implicación del espectador y complejidad estructural) eran en un comienzo indisolubles; por ello los grupos y artistas pioneros en las tecnologías interactivas aplicadas a la escena propusieron numerosas obras en las que se le concedía un lugar relevante al espectador en la actualización de la pieza. En una primera etapa la tecnología interactiva se pensaba como el instrumento ideal para introducir de manera coherente y total al espectador en la recepción (y creación o actualización) de la obra, mientras que en un segundo momen-

\footnotetext{
${ }^{6}$ Entrevista personal con Frieder Weiss, Berlín, 29.01 .2006.
} 
to se abandonaron estos propósitos emancipatorios del espectador para a cambio orientarse hacia la creación de una obra escénica de calidad, de una obra compleja, abierta y procesual que se autogenera en el diálogo entre sus elementos. A lo largo de su desarrollo, los creadores de obras escénicas interactivas fueron abandonando los propósitos emancipadores para centrar su atención sobre un resultado escénico de mayor valor visual.

Por ello, el tipo de interacción al que actualmente se hace referencia con escenario sensible en el marco de una representación no se refiere al trato recíproco entre obra y espectador, sino a las posibilidades que se le ofrecen por medio de la tecnología al bailarín o al actor de dialogar con los parámetros de la representación. No cabe ninguna duda de que este fenómeno debe denominarse interacción, pero no en el sentido que se le ha venido dando, con connotaciones liberadoras y emancipadoras en relación con el receptor. Actualmente, la única implicación de un espectador ante una pieza escénica interactiva se limita a la de reconocer el diálogo entre bailarín o actor y aparato técnico, así como a dotar de sentido a la obra. Un propósito emancipador del receptor, según el cual este asume un papel activo en la creación o ejecución de la obra es prácticamente inexistente en las piezas escénicas interactivas actuales.

Dieter Daniels ofrece una explicación a este fenómeno; ha señalado que el arte interactivo se sitúa entre dos paradigmas radicalmente distintos, el de Brecht y el de Turing ${ }^{7}$; el primero se basa en una comprensión social de la interacción como comunicación entre individuos. En cambio, el segundo parte de una consideración meramente tecnológica de la interacción, entendida como diálogo entre hombre y máquina. La interacción de los años sesenta entre público, obra y artistas estaba presidida por una voluntad de reivindicación ideológica, estética y política, enfrentada al arte elitista burgués y con un propósito claro de cambio social (Daniels, 2003: 142-169). Se trataba de crear un nuevo campo artístico subversivo que se situara más allá de los géneros, las categorías y las instituciones al uso. En los años setenta se produjo una combinación de ambos paradigmas, según la cual la ideología encontraría su realización a través de la tecnología. A finales de los años noventa este modelo se invierte; el poder movilizador de los medios se ha diluido en la integración de estos en el mercado, mientras que la hegemonía medial dicta y determina por sí misma, de acuerdo con sus características

7 Sobre el concepto controvertido de interacción véase: Broadhurst (2006: 141-152), Gianetti (2002: 111-164), Lischka / Weibel (1989), Hünnekens (1997), Lischka / Weibel (1989); específicamente dentro del ámbito escénico: Evert (2003: 156-190), Schiller (2002: 164-243) y el volumen 40-41 de la revista Nouvelles de danse. 
propias e independientemente de una ideología aplicada a los medios que persiga cambios sociales, estéticos, culturales y económicos. La interacción en este nuevo paradigma, según Daniels, no tiene una legitimación estética, sino que se corresponde con los principios básicos de la tecnología digital.

A lo largo de los últimos 40 años se ha ido así produciendo dentro del marco del término interacción un peculiar desplazamiento que lleva desde un extremo hasta su opuesto, desde la participación del espectador hasta el refinamiento de las técnicas de generación de un espectáculo cada vez más sorprendente. En cualquiera de los casos, a lo largo de esta evolución es posible discernir un indiscutible giro de la imagen hacia lo performativo, en el que se ha dado una integración plena de elementos audiovisuales y escénicos: de esta forma la imagen y el cuerpo han entrado en un diálogo a todas luces fructífero y que ha dado lugar a una serie de géneros artísticos que todavía están abiertos a exploraciones futuras, tales como el escenario interactivo y la instalación medial interactiva ${ }^{8}$. La imagen ha dejado de ser bidimensional, unidireccional y ajena a toda intervención para verse afectada por el cuerpo y la voz del actor, para dejarse manipular hasta llegar a una ductilidad que le permite entablar un verdadero diálogo físico en la escena.

\section{REFERENCIAS BIBLIOGRÁFICAS}

AA.VV. (2004). Interagir avec les technologies numériques. Nouvelles de Danse 40-41. Bruxelles: Contredanse.

BROADHURST, S. (2006). «Intelligence, Interaction, Reaction and Performance». En Performance and Technology. Practices of Virtual Embodiment and Interactivity, Susan Broadhurst, Josephine Machon (eds.), 141-152. New York: Palgrave.

DANIELS, D. (2003). «Strategien der Interaktivität». En Medien Kunst Interaction. Die 80er und 90er Jahre in Deutschland, Rudolf Frieling, Dieter Daniels (eds.), 142-169. Wien: Springer.

DINKLA, S. (1997). Pioniere Interaktiver Kunst von 1970 bis heute. Myron Krueger, Jeffrey Shaw, David Rockeby, Lynn Hersman, Grahame Weibren, Ken Feingold. Ostfildern: Cantz.

${ }^{8}$ La imagen de la realidad virtual no ha sido incluida en este esbozo histórico, ya que el cuerpo en esta tecnología por lo general ha jugado un papel insignificante, estando la experiencia del usuario prácticamente reducida a su dimensión visual: la interfaz por excelencia de contacto con el mundo virtual ha sido el dataglove (guante de datos), mientras que se ha ignorado el resto de cuerpo. 
DUGUET, A. M. (1997). «Jeffrey Shaw. Vom Expanded CInema zur virtuellen Realität». En Jeffrey Shaw -eine Gebrauchanweisung. Vom Expanded Cinema zur Virtuellen Realität, Peter Weibel, Anne Marie Duguet, Heinrich Klotz (eds.). Ostfildern: Cantz.

ECO, U. (1984). Obra abierta. Barcelona: Planeta - De Agostini.

EVERT, K. (2003). DanceLab. Zeitgenössischer Tanz und Neue Technologien. Würzburg: Königshausen und Neumann.

FISCHER-LICHTE, E. (2004). Ästhetik des Performativen. Frankfurt am Main: Suhrkamp.

GIANETTI, C. (2002). Estética digital. Sintopía del arte, la ciencia y la tecnología. Barcelona: L'Angelot.

HÜNNEKENS, A. (1997). Der Bewegte Betrachter. Theorien der interaktiven Medienkunst. Köln: Wienand Verlag.

LISCHKA G. J. \& WEIBEL, P. (eds.) (1989). Im Netz der Systeme. Für eine interaktive Kunst: Ars Electronica Linz. Kunstforum International 103.

ROSINY, C. (1999). Videotanz. Panorama einer intermedialen Kunstform. Zurich: Chronos.

SCHILLER, G. (2002). «Interaktivität als choreographisches Phänomen». En Tanz und Technologie. Auf dem Weg zur medialen Inszenierung, Söke Dinkla \& Martina Leker (eds), 164-175. Berlin: Alexander Verlag.

SHAW, J. (1989). «Modalitäten einer interaktiven Kunstausübung». En Im Netz der Systeme. Für eine interaktive Kunst: Ars Electronica Linz, Peter Weibel \& Gerhard Johann Lischka (eds.), 204-209. Kunstforum International 103.

WECHSLER, R. (2001). «Danza interattiva: dilemmi dell'arte nell'era dei computer». En La scena digitale. Nuovi media per la danza, Armando Menicacci \& Emmanuele Quinz (eds.), 191-202. Venezia: Marsilio.

- (2003). «Artistic Considerations in the Use of Motion Tracking with Live Performers: a Practical Guide». En Performance and Technology. Practices of Virtual Embodiment and Interactivity, Susan Broadhurst \& Josephine Machon (eds.), 60-77. New York: Palgrave.

WEIBEL, P. (1997). «Shaw -eine Gebrauchanweisung». En Jeffrey Shaw -eine Gebrauchanweisung. Vom Expanded Cinema zur Virtuellen Realität, Peter Weibel, Anne Marie Duguet, Heinrich Klotz (eds.). Ostfildern: Cantz. 
WEIBEL, P. \& LISCHKA G. J. (1989). «Polylog. Für eine interaktive Kunst». En Im Netz der Systeme. Für eine interaktive Kunst: Ars Electronica Linz, Gerhard Johann Lischka \& Peter Weibel (eds.), 65-86. Kunstforum International 103.

WEINBREN, G. (1992). «Ein interaktives Kino». En Interface. Elektronische Medien und künstlerische Kreativität, Klaus Peter Dencker (ed.), 58-64. Hamburg: Hans Bredow Institut. 